\title{
THE DETERMINATION OF BLOOD VISCOSITY IN MAN BY A METHOD BASED ON POISEUILLE'S LAW
}

\author{
BY BERNARD PIROFSKY
}

\author{
(From The Department of Medicine, New York University Post Graduate Medical School, \\ and The Fourth Medical [N.Y.U.] Division, Bellevue Hospital, New York City)
}

(Submitted for publication June 26, 1952; accepted December 18, 1952)

The viscosity of the blood is an important factor in any consideration of blood flow or peripheral resistance (1). In addition, a change in blood viscosity has been implicated in many clinical conditions (2-6). The determination of blood viscosity in man, however, has been limited by poor techniques of doubtful accuracy. With the methods now available, blood is removed from the body and its viscosity determined relative to water. This relative viscosity is of limited value in any quantitative hemodynamic study, and cannot be converted into accurate absolute values because of changes occurring in the blood subsequent to its removal from the body. If the viscosity of blood in its unchanged state could be determined, an important experimental value would be made available. A technique for such a measurement is now described.

\section{METHOD}

According to Poiseuille's law (7), during laminar flow of a homogeneous fluid in a tube of constant diameter, the frictional energy loss bears a linear relationship to the volumetric rate of flow and is independent of the vessel wall. Absolute viscosity of a fluid can be determined by passing the fluid through a tube of known length and radius while measuring the rate of flow and the difference in pressure between the ends of the tube. This relationship is expressed by the following formula:

$$
\eta=\frac{f}{q} \cdot \frac{\pi r^{4}}{81},
$$

where $\eta=$ absolute viscosity in grams sec. per $\mathrm{cm}^{2} ; \mathrm{q}=$ volumetric rate of flow as $\mathrm{cm}^{3}$ per sec.; $r=$ radius and $1=$ length of tube in $\mathrm{cm}$.; $f=$ frictional loss of energy as $\mathrm{cm}^{2}$ per gram (8). If the absolute viscosity is expressed in dyne sec. per cm.', the unit of viscosity is the poise or centipoise (9).

It has been shown that in vessels greater than $0.3 \mathrm{~mm}$. diameter, blood behaves as a homogeneous mixture (10), and at physiological pressures its flow is laminar (8). According to formula (1), viscosity is independent of the character of the vessel wall and a tube may be substituted for a blood vessel to allow an accurate determination of length and radius. The insertion of such a branching system does not invalidate Poiseuille's law. If a needle is to act as the tube, the factor $\pi r^{4} / 81$ is more readily obtained by measurements of flow rates of distilled water at known pressures than by attempted determination of the cross sectional area of the needle, the bore of which is not constant. This was done by measuring the rate of flow of distilled water at $20^{\circ} \mathrm{C}$ from a reservoir of known height. The following relationship then holds:

$$
\frac{\pi \mathrm{r}^{4}}{81}=\frac{(\eta)(\mathrm{q})}{\mathrm{f}} \text {. }
$$

Substituting the absolute viscosity of water at $20^{\circ} \mathrm{C}$, and converting it into centipoise, the needle factor $\mathrm{X}$ is derived from the formula:

$$
X=\frac{(98850)(q)}{f}
$$

where $q$ and $f$ have the meaning given above. Experimentally it was found that a long no. 18 gauge needle (length $90 \mathrm{~mm}$; inside diameter $0.838 \mathrm{~mm}$.) served best for accurate calibration and viscosity determination. This needle has an internal bore well above the critical $0.3 \mathrm{~mm}$. diameter that has been found necessary for blood to act as a homogeneous mixture in a tube (10). Green's (8) criteria that the minimum length of a tube should be at least twenty times the diameter, in order to minimize pressure losses, is also satisfied. With such a calibrated needle, the viscosity of whole blood may be determined by the relationship:

$$
\eta=\frac{(\mathrm{f})(\mathrm{X})}{\mathrm{q}} .
$$

In order to express viscosity in a less cumbersome form, conversion to poise units is desirable. This is accomplished by dividing first by a factor of 980 , which converts gram sec. per $\mathrm{cm}^{2}$ to dyne sec. per $\mathrm{cm}^{2}$, and then by 100 to convert poises to centipoise, as follows:

$$
\eta=\frac{(\mathrm{f})(\mathrm{X})}{(\mathrm{q})(98000)},
$$

where $f$ and $q$ are calculated as follows. A calibrated needle connected to a saline manometer is inserted into a large superficial vein. The pressure in the vein is raised to 200 to $400 \mathrm{~mm}$. water by lowering the vein well below the level of the heart. When the pressure at the needle point has stabilized the glass connector to the saline manometer is disconnected. Blood is allowed to flow freely through the needle and is collected in a calibrated heparinized tube over a period timed by stop watch; the pressure within the vein is immediately rechecked. The flow rate $(q)$ is then calculated as $\mathrm{cm}^{2}$ per sec. and 
should be kept at the level of $0.1 \mathrm{~cm}^{3}$ per sec. In this fashion, approximately thirty seconds will be sufficient to collect the $3 \mathrm{~cm}^{3}$ of blood necessary for an accurate measurement of flow rate. On the collected blood, hematocrit determinations were made by centrifuging the specimen in a Wintrobe tube for thirty minutes at 3,000 r.p.m. The pressure as read on the manometer plus atmospheric pressure represents the pressure head at the needle point. As the end of the needle is exposed to the atmosphere during blood flow, the pressure gradient is represented by the determined venous pressure. If the venous pressure in $\mathrm{cm}$. is multiplied by the density of the fluid in the manometer, pressure is converted into $\mathrm{cm}^{2}$ per gram and represents the frictional loss of energy during blood flow, or f. Using a saline manometer, the density conversion factor is 1 , and the venous pressure determination in $\mathrm{cm}$. may be substituted for $\mathrm{f}$. Absolute viscosity is then calculated in centipoises according to formula (5).

Three major inaccuracies may occur with this method. (1) It is well known how variable venous pressure may be. The subject should be relaxed and the volumetric rate of blood flow should not be measured until at least three similar readings of venous pressure have been obtained. The venous pressure should be rechecked immediately after the determination of the flow rate, and if a gross discrepancy exists between this and previous measurements, the blood flow determination must be discarded. When minor differences exist, a mean value should be taken as the venous pressure during the thirty second period of blood flow determination. (2) The assumption is made that the venous pressure is the same during its measurement and during the blood flow determination. However, it is known that the pressure head acting on a tube increases in a change from the static state to active motion (9). This error in the method is partially off-set by the fact that the needle does not completely occlude the vein, and a static state does not exist. The magnitude of this error, however, has not yet been determined. (3) Changes in blood temperature during determination of viscosity will lead to inaccurate results. Accordingly, longer needles and flow rates less than $0.1 \mathrm{~cm}^{3}$ per sec. should be avoided unless the needle is thermostatically jacketed.

Blood viscosity is dependent on the volume of packed red cells and the concentration of plasma constituents. Normally the erythrocytes are responsible for the major contribution to the viscosity. However, in certain conditions (e.g., cryoglobulinemia) the presence of highly asymmetric molecules play a major role and this may be an important factor in the clinical picture. In this study an attempt was made to correlate the hematocrit with the absolute blood viscosity. Accordingly, patients with abnormal plasma constituents, or erythrocytes of abnormal size and shape, were excluded from the study group. In this way it was hoped to arrive at the normal relationship of absolute viscosity to the hematocrit.

\section{RESULTS}

On a hospital population, selected as above, 154 absolute viscosity determinations were carried out on 72 patients (Table I). A single determination was made on nineteen patients; thirty patients had two determinations, eighteen patients three determinations, four patients four, and one patient five measurements of viscosity. In the 53 patients whose viscosity levels were repeated, the average intra-subject standard deviation was 0.12 . Thus, at a hematocrit ranging about 45 per cent, the viscosity was determined to be $2.70 \pm 0.12$ centipoises; the coefficient of variation at this level is therefore 4.5 per cent. This means that when one observation is recorded using the above technique, the true value will be within 8.9 per cent of the observation in 95 per cent of the cases. This is well within the range of error encountered in most hemodynamic procedures today.

Determinations were made at hematocrit ranges from 14 per cent to 76 per cent and mean absolute viscosity levels of 1.32 to 7.80 centipoises were found. When the hematocrit ranged from 40 per cent to $\mathbf{4 5}$ per cent, absolute viscosity ranged from 2.30 to 2.75 centipoises. This value falls within and effectively narrows the range of normal viscosity approximated by Green (8) as 1.75 to 2.80 centipoises, which was obtained by converting various in vitro determinations to absolute values. The results are summarized in Table I.

When the absolute viscosity is plotted against the hematocrit (Figure 1), a smooth curve is obtained which closely follows the slope of a formula derived by Hatschek $(11,12)$ :

$$
\eta=\frac{\eta_{0}}{1-\phi^{1}},
$$

where $\eta=$ viscosity of whole blood, $\eta_{0}=$ viscosity of plasma, and $\phi=$ hematocrit expressed as a fraction. Hatschek's formula as presented in Figure 1 is derived from the calculations of Trevan (13) by converting relative to absolute units. This has been done by using Trevan's finding of a relative viscosity of 4.42 at a hematocrit of 46 per cent as equal to the experimentally found absolute viscosity of 2.70 centipoises at the same hematocrit. 
TABLE I

The absolute blood viscosity and hematocrit of 72 patients

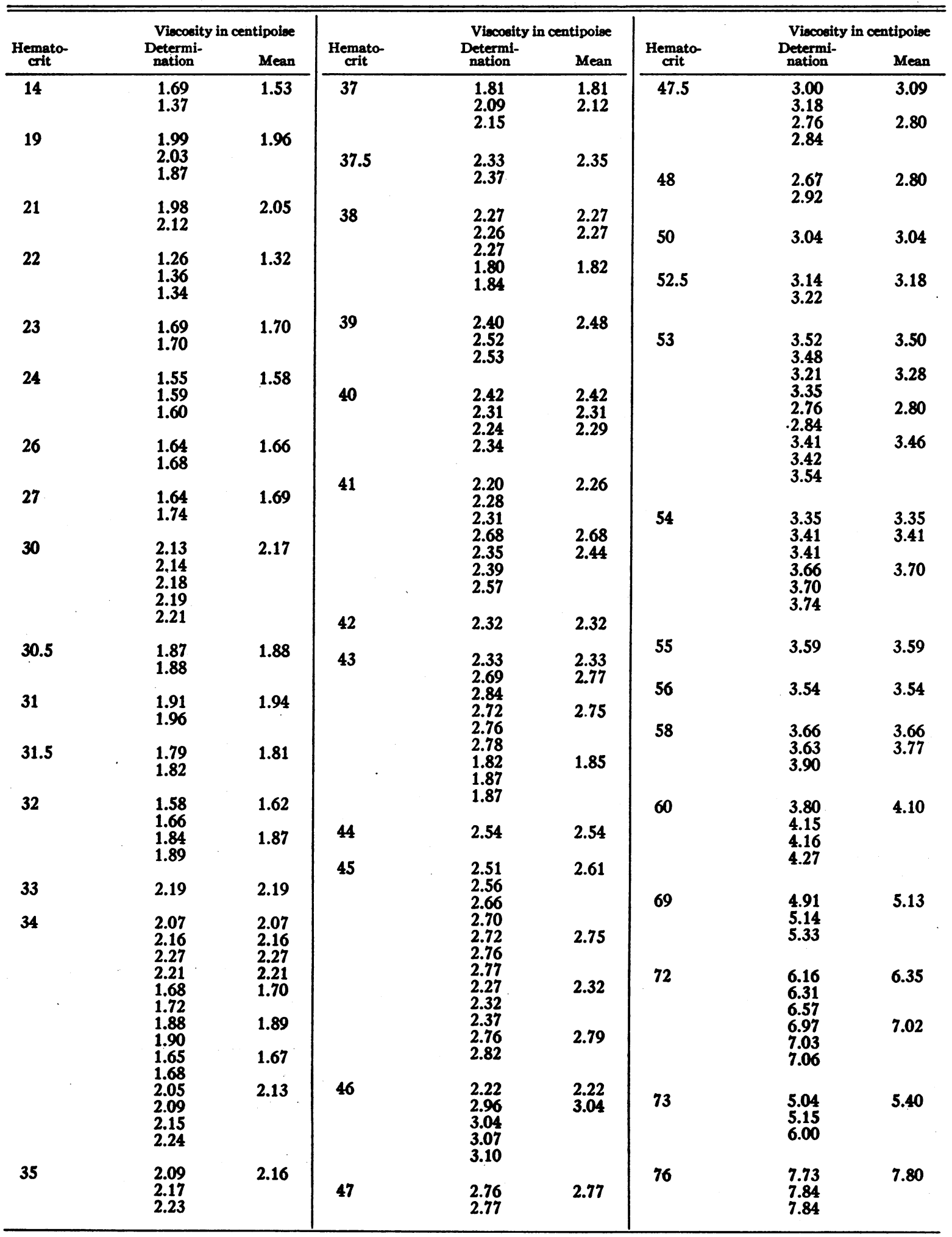




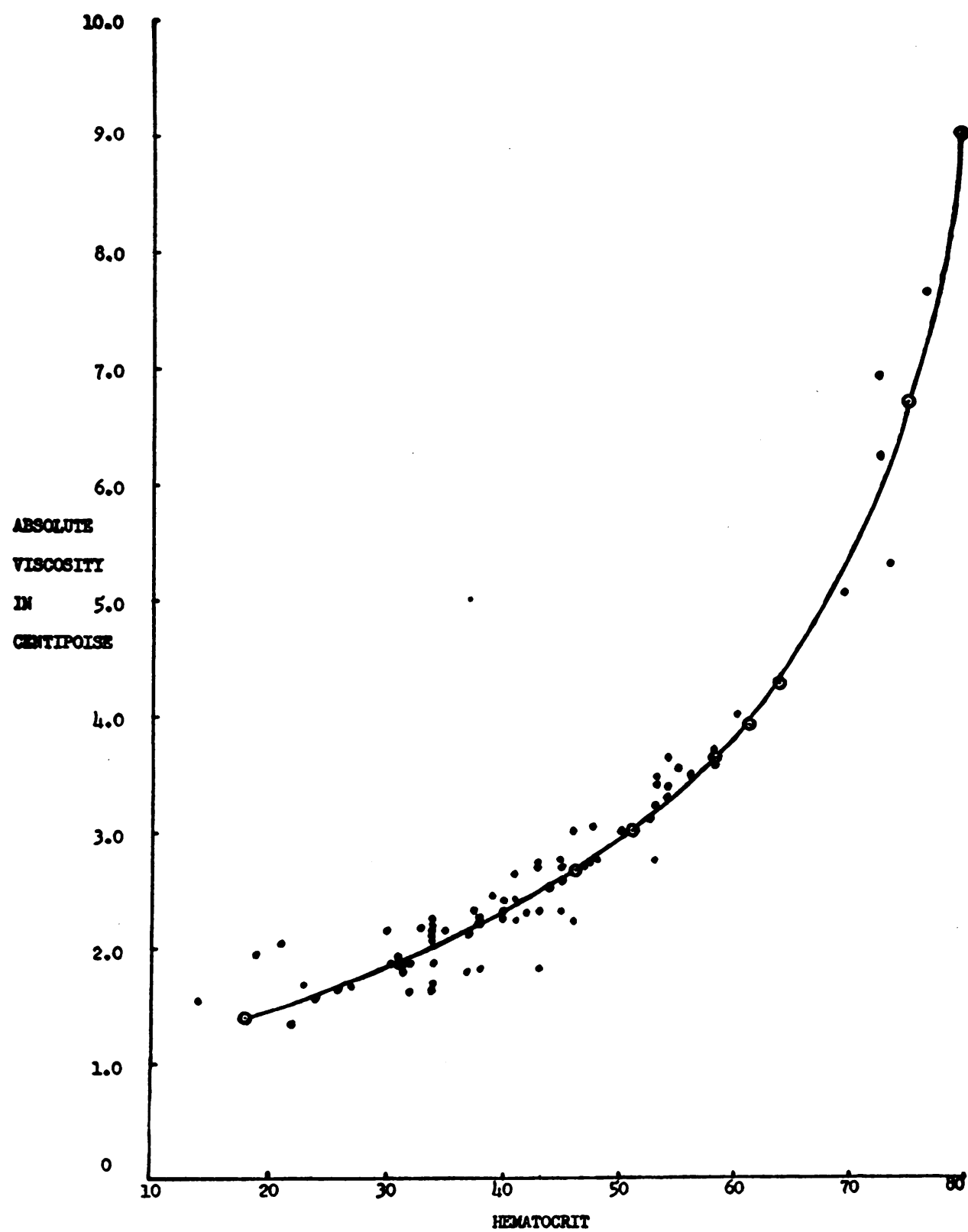

Fig. 1. The Relationship Between the Absolute Viscosity of Whole Blood in Centipoise and the Hematocrit

The curve represents the theoretical relationship expressed by Hatschek's formula and is derived from the calculations of Trevan as explained in the text.

\section{DISCUSSION}

An "ideal fluid" is one in which internal forces at any internal section are always normal to the section, even during motion; that is, forces are purely pressure. Since there can be no tangential force, the fluid is frictionless. This type of fluid does not exist. In an "actual fluid," in addition to the pressure forces, tangential or shearing stresses always come into play whenever motion takes place. This shearing stress gives rise to fluid friction, and is due to the property of the fluid termed viscosity (9).

Many methods have been devised for the determination of blood viscosity. The original attempts 
$(14,15,16)$ were inaccurate and were replaced by the method of Hess (17). This technique measures the comparative rate of flow of blood and water in similar tubes as an equal pressure is applied. General dissatisfaction with the method has been made evident by repeated attempts to produce a more accurate technique (13, 18-22). All of these methods were of the in vitro type and yielded values for the viscosity of blood relative to water.

The removal of blood from the body produces many changes in the blood which prevent a conversion of relative to absolute blood viscosity. Any method endeavoring to determine accurately blood viscosity must standardize the following factors: (a) Blood temperature. Burton-Opitz (23) showed that with cooling of blood, viscosity increased. This increase has been said to range from 0.8 per cent $(24)$ to 2.0 per cent $(8,16)$ per degree centigrade of cooling. From Langstroth's (25) experimental findings, however, there is approximately a 3.0 per cent rise in viscosity with every degree centigrade of cooling. (b) Fluidity of blood. As viscosity is calculated by determining flow rate, clotting will lead to erroneous values. Brundage (19) found that in vitro measurements of viscosity without anticoagulants were unsuccessful. Yet rendering the blood fluid by defibrination (26), heparin (21) and hirudin (27) has been found to change blood viscosity. The use of oxalate salts which change cell volume is also inaccurate, as viscosity varies with cell volume $(28,29)$. (c) Sedimentation of the blood. The volume of packed red cells influences blood viscosity. Therefore, blood settling during determination of viscosity will lead to erroneous values. (d) Blood carbon dioxide content. It has been shown (25, 30 ) that a change in the carbon dioxide content of the blood changes its viscosity, with the viscosity rising as the carbon dioxide content increases. Accordingly, it is necessary to equilibrate blood to atmospheric tension of carbon dioxide for accurate in vitro determinations. (e) Tube diameter. To determine viscosity according to Poiseuille's law, the fluid must be homogeneous. Fahraeus (10) found that blood acted as a homogeneous mixture only in tubes of $0.3 \mathrm{~mm}$. diameter or larger. Below this point, viscosity decreases with the reduced diameter of the tube and does not follow Poiseuille's law. (f) Pressure-flow relationship.
Poiseuille's law can be applied to the motion of fluids only when that motion is laminar. Applying Reynold's equation, it is found that physiological blood flow is laminar except possibly in the aorta during the ejection phase (8). Bayliss (31) found that the change of viscosity with velocity of flow is marked at low velocities, but becomes less evident as velocity increases. At physiological pressures an optimum range of velocity exists so that viscosity is unaffected by flow rate (17). Fahraeus (10) used a pressure of $100 \mathrm{~mm}$. $\mathrm{Hg}$ and considered that far above the critical level. Whittaker and Winton (32) found that pressures of $30 \mathrm{~mm}$. to $120 \mathrm{~mm}$. $\mathrm{Hg}$ maintained accurate viscositypressure relationships.

In order to compare in vivo and in vitro viscosity determinations, Whittaker and Winton (32) perfused the blood vessels of the hind limb of a dog. As expected from the capillary diameter, they found intravascular viscosity lower than viscosimetric values. Because of this, "apparent viscosity" was estimated on the basis of a modification of Poiseuille's law and no attempt was made to determine absolute viscosity. Mendlowitz (33) also employed this approach in determining digital intravascular viscosity in man. Objections can be raised in this application of Poiseuille's law for the determination of intracapillary viscosity. In his study on capillaries, Landis (34) found that Poiseuille's law could not be applied to a quantitative consideration of pressure drops in capillaries. This is borne out by Green's (8) demonstration that capillary blood flow is of the plastic type representing an interaction between the walls of the tube and the liquid. This is in contrast to viscous flow which represents solely an interaction between the layers of the fluid.

In the present method Poiseuille's law is used to determine the viscosity of blood as it flows in vessels $0.3 \mathrm{~mm}$. diameter or larger. The advantage of the method is that viscosity is determined without changes in the blood and may be expressed in absolute units, allowing direct application in quantitative hemodynamic calculations.

The demonstration that the absolute blood viscosity is related to the hematocrit according to the formula described by Hatschek $(11,12)$ permits examination of the behavior of that component of the viscosity attributable to the red cell mass. Hatschek originally described this relation- 
ship for colloidal systems and found it applicable to systems with corpuscular concentrations of 65 per cent or greater. Trevan (13) showed that this formula applied to blood, demonstrating a \pm 1 per cent relationship at hematocrits above 45 per cent. The flat shape and easy deformability of the erythrocyte was believed to allow the application of this formula at lower hematocrits. Whittaker and Winton (32) modified the formula as given above (formula 6) and found it applicable for hematocrit ranges from 10 to 80 per cent. In their review of this relationship, they found that the slope of the derived curve was independent of viscosity units or pressure and could provisionally be adopted as an empirical relation between hematocrit and viscosity. Trevan made in vitro measurements of viscosity and Whittaker and Winton used a biological viscometer. A similar relationship between absolute blood viscosity and the hematocrit has been demonstrated in the present study.

The relationship of hematocrit to intracapillary blood viscosity described by Whittaker and Winton (32) and confirmed by Mendlowitz (33) was not found. This demonstrates again that blood viscosity in the capillaries and in vessels of $0.3 \mathrm{~mm}$. diameter or larger are of different magnitudes. When the two levels of viscosity are compared, there is a wide divergence at low hematocrits and a closer approximation in polycythemic patients.

The linear relationship between viscosity and hematocrit described by Holbrook and Watson (35) and Nygaard, Wilder, and Berkson (36) was not confirmed. The latter observers, however, found it necessary to exclude cases of polycythemia in order to arrive at a linear relationship. The error introduced by excluding these values is obvious when it is realized that in polycythemia there is a sharp rise in the ratio of viscosity to hematocrit.

By varying mixtures of erythrocytes and plasma, Evans (37) found a linear relationship between the hematocrit and the logarithm of the viscosity. On the limited data available it was not possible to confirm or deny this relationship.

Although knowing the hematocrit allows the absolute blood viscosity to be approximated, it should be stressed that this is possible only when the erythrocytes are normal in size and shape, and the plasma constituents are of normal concentra- tion. There are several suggestions in the literature of disease states in which blood viscosity levels are abnormal. Sickle cell anemia (38), leukemia (39), hypercholesterolemia (40), hyperglycemia (41), and changes in plasma protein values (42) are all said to cause changes in blood viscosity. As these observations were made with methods of doubtful accuracy, detailed reinvestigation is necessary before conclusions can be drawn.

\section{SUMMARY}

1. A method for the determination of absolute blood viscosity in vessels of $0.3 \mathrm{~mm}$. diameter or larger is described. This technique involves venepuncture, a determination of venous pressure, and the measurement of flow rate of blood through a calibrated needle.

2. In 72 patients the hematocrit was correlated with the absolute viscosity and found to follow closely the slope of a curve derived from Hatschek's formula. Patients with hematocrits from 14 to 76 per cent were studied and were found to have absolute viscosity levels of 1.32 to 7.80 centipoises. At hematocrits of 40 per cent to 45 per cent, blood viscosity was found to range from 2.30 to 2.75 centipoises.

3. The average intrasubject standard deviation utilizing this method was found to be 0.12 with a coefficient of variation of 4.5 per cent.

4. The use of Hatschek's formula and the hematocrit to predict absolute blood viscosity is discussed. Some of the conditions leading to an abnormal hematocrit-viscosity relationship are mentioned.

\section{REFERENCES}

1. Seligman, A. M., Frank, H. A., and Fine, J., Traumatic shock. XII. Hemodynamic effects of alterations of blood viscosity in normal dogs and in dogs in shock. J. Clin. Invest., 1946, 25, 1.

2. Harris, I., and McLoughlin, G., The viscosity of the blood in high blood pressure. Quart. J. Med., 1930, 23, 451.

3. Brundage, J. T., Cantarow, A., and Griffith, R. S., Viscosity, proteins, and lipids of blood plasma in essential hypertension. Am. J. Med. Sci., 1936, n.s., $192,30$.

4. Markson, A., Blood viscosity in congestive failure. Glasgow Med. J., 1936, 125, 201.

5. Ferrer, M. I., Harvey, R. M., Cathcart, R. T., Webster, C. A., Richards, D. W., and Cournand, A., Digoxin in chronic cor pulmonale. Circulation, 1950, 1, 161. 
6. Schneider, R. A., Recurrent thrombophlebitis: An experimental study of life situations and emotions and the clotting time and relative viscosity of the blood. Am. J. Med. Sci., 1951, 222, 562.

7. Poiseuille, J. L. M., Recherches experimentales sur le movements des liquides dans les tubes de très petits diamètres. Comptes rend. Acad d. sc., 1840, 11, 961, 1041.

8. Green, H. D., in Medical Physics, Glasser, O., editor. Yearbook Publishers, Inc., Chicago, Ill., 1944, 1, 216.

9. Daugherty, R. L., Hydraulics, a Text on Practical Fluid Mechanics, 43 ed. McGraw-Hill Co., New York, N. Y., 1937.

10. Fåhræus, R., and Lindqvist, T., The viscosity of the blood in narrow capillary tubes. Am. J. Physiol., 1931, 96, 562.

11. Hatschek, E., 1911, quoted by Trevan, J. W. (13).

12. Hatschek, E., The Viscosity of Liquids. G. Bell and Sons Ltd., London, 1928.

13. Trevan, J. W., The viscosity of the blood. Biochem. J., 1918, 12, 60.

14. Denning, A. duP., and Watson, J. H., A simple form of clinical viscosimeter. Lancet, 1906, 2, 89.

15. Determann, H., Ein einfaches, stets gebrauchfertiges blutviskosimeter. Munch. med. Wschr., 1907, 54, 1130.

16. McCaskey, G. W., The viscosity of the blood, its value in clinical medicine. J. A. M. A., 1908, 51, 1653.

17. Hess, W., Ein neuer apparat zur bestimmung der viskosität des blutes. Munch. med. Wschr., 1907, 54, 1590.

18. Ostwald, W., Ueber die geschwindigkeitsfunktion der viskosität disperser systeme. Kolloid-Ztschr., 1925, 36, 99.

19. Brundage, J. T., Blood and plasma viscosity determined by the method of concentric cylinders. Am. J. Physiol., 1935, 110, 659.

20. T'ang, H. Y., and Wang, S. H., The clinical application of plasma viscosity determinations. Chin. Med. J., 1940, 57, 546.

21. Copley, A. L., Krchma, L. C., and Whitney, M. E., Humoral rheology. I. Viscosity studies and anomalous flow properties of human blood systems with heparin and other anticoagulants. J. Gen. Physiol., 1942, 26, 49.

22. Mann, F. D., Clinical viscometer. Am. J. Clin. Path., 1948, 18, 79.

23. Burton-Opitz, R., The effect of changes in temperature upon the viscosity of the "living" blood. $\mathrm{J}$. Exp. Med., 1906, 8, 59.

24. Hess, W., Die viskosität des blutes bei gesunden. Deutches Archiv. f. klin. Med., 1908, 94, 404.
25. Langstroth, L., Blood viscosity. I. Conditions affecting the viscosity of blood after withdrawal from the body. J. Exp. Med., 1919, 30, 597.

26. Oberst, F. W., Specific volume of plasma and serum proteins in pregnant and parturient women and their newborn children as derived from viscosity measurements. J. Clin. Invest., 1939, 18, 799.

27. Burton-Opitz, R., The viscosity of the blood. J. A. M. A., 1911, 57, 353.

28. Baldes, E. J., Essex, H. E., and Markowitz, J., The physiologic action of rattlesnake venom. (Crotalin). $\mathrm{X}$. Influence of crotalin on the viscosity of blood. Am. J. Physiol., 1921, 97, 26.

29. Tanaka, Y., On the relation between the size and the viscosity of the red cells. Japan. J. Med. Sci., III, Proc. Sup. Physiol. Soc., Biophysics, 1936, 4, 110.

30. Welsh, W. H., Viscosity of the blood. Heart, 1911, 3, 118.

31. Bayliss, L. E., 1933, quoted by Whittaker and Winton (32).

32. Whittaker, S. R. F., and Winton, F. R., The apparent viscosity of blood flowing in the isolated hindlimb of the dog, and its variation with corpuscular concentration. J. Physiol., 1933, 78, 339.

33. Mendlowitz, M., Effect of anemia and polycythemia on digital intravascular blood viscosity. J. Clin. Invest., 1948, 27, 565.

34. Landis, E. M., Poiseuille's law and the capillary circulation. Am. J. Physiol., 1933, 103, 432.

35. Holbrook, A. A., and Watson, M. V., Blood viscosity. Am. J. Med. Sci., 1939, n.s., 198, 750.

36. Nygaard, K. K., Wilder, M., and Berkson, J., The relation between viscosity of the blood and the relative volume of erythrocytes (hematocrit values). Am. J. Physiol., 1935, 114, 128.

37. Evans, P., Blood viscosity. Lancet, 1942, 1, 162.

38. McCord, W. M., Kelley, W. H., Switzer, P. K., and Culp, F. B., Viscosity studies of erythrocytes from persons with sickle cell disease. Proc. Soc. Exp. Biol. and Med., 1948, 69, 19.

39. Stephens, D. J., Relation of viscosity of blood to leucocyte count with special reference to chronic myelogenous leucemia. Proc. Soc. Exp. Biol. and Med., 1936, 35, 251.

40. Fishberg, E. H., Significance of changes of viscosity in pathological sera. J. Biochem., 1930, 85, 465.

41. Burton-Opitz, R., The effect of intravenous injections of solutions of dextrose upon the viscosity of the blood. J. Exp. Med., 1906, 8, 240.

42. Chopra, R. N., and Choudhury, S. G., Studies in physical properties of different sera. Part III. Viscosity. Indian J. Med. Research, 1929, 16, 939. 